NBER WORKING PAPER SERIES

\title{
U.S. HIGH-SKILLED IMMIGRATION, INNOVATION, AND ENTREPRENEURSHIP: EMPIRICAL APPROACHES AND EVIDENCE
}

\author{
William R. Kerr \\ Working Paper 19377 \\ http://www.nber.org/papers/w19377 \\ NATIONAL BUREAU OF ECONOMIC RESEARCH \\ 1050 Massachusetts Avenue \\ Cambridge, MA 02138 \\ August 2013
}

Comments are appreciated and can be sent to wkerr@hbs.edu. The original version of this paper was prepared for the World Intellectual Property Organisation (WIPO) Experts Meeting on "Intellectual Property, the International Mobility of Knowledge Workers and the Brain Drain" (April 2013, Geneva). WIPO provided an honorarium for the preparation and presentation of this paper. I am grateful to Jinyoung Kim, Christiane Kuptsch, Carsten Fink, Ernest Miguelez, and WIPO conference participants for their comments and suggestions. The views expressed herein are those of the author and do not necessarily reflect the views of the National Bureau of Economic Research.

NBER working papers are circulated for discussion and comment purposes. They have not been peerreviewed or been subject to the review by the NBER Board of Directors that accompanies official NBER publications.

(C) 2013 by William R. Kerr. All rights reserved. Short sections of text, not to exceed two paragraphs, may be quoted without explicit permission provided that full credit, including $\odot$ notice, is given to the source. 
U.S. High-Skilled Immigration, Innovation, and Entrepreneurship: Empirical Approaches and Evidence

William R. Kerr

NBER Working Paper No. 19377

August 2013

JEL No. F15,F22,J15,J31,J44,L14,L26,O31,O32,O33

\begin{abstract}
High-skilled immigrants are a very important component of U.S. innovation and entrepreneurship. Immigrants account for roughly a quarter of U.S. workers in these fields, and they have a similar contribution in terms of output measures like patents or firm starts. This contribution has been rapidly growing over the last three decades. In terms of quality, the average skilled immigrant appears to be better trained to work in these fields, but conditional on educational attainment of comparable quality to natives. The exception to this is that immigrants have a disproportionate impact among the very highest achievers (e.g., Nobel Prize winners). Studies regarding the impact of immigrants on natives tend to find limited consequences in the short-run, while the results in the long-run are more varied and much less certain. Immigrants in the United States aid business and technology exchanges with their home countries, but the overall effect that the migration has on the home country remains unclear. We know very little about return migration of workers engaged in innovation and entrepreneurship, except that it is rapidly growing in importance.
\end{abstract}

William R. Kerr

Harvard Business School

Rock Center 212

Soldiers Field

Boston, MA 02163

and NBER

wkerr@hbs.edu 


\section{Introduction}

The global migration of talented workers is a big topic, with lots of policy interest and a growing number of academic studies providing insights into its economic consequences (e.g., Freeman 2006, Clemens 2011). But all things considered, the topic is vastly under-studied compared to its economic importance. To give a sense of this gap, we review below fewer than 50 academic articles that touch upon the link of immigration and innovation in the United States, even with very broad definitions, while noting that immigrants account for approximately a quarter of U.S. inventors. This mismatch in importance is striking, and it leaves the field and policy discussions anchored around policy briefs and opinion pieces from sources that frequently have biased agendas. Consider also a comparison against venture capital (VC) investments. VC investments impacted fewer patents than immigrant inventors over the last three decades, but the academic literature regarding $\mathrm{VC}$ is orders of magnitude larger.

Moreover, a better and accurate understanding of these topics is of immediate policy importance. The H-1B visa program, which is described in more detail in the appendix, is a primary entry route for high-skilled immigrants to the United States for employment-based visas. The U.S. government began receiving requests for H-1B visas for fiscal year 2014 on April 1, 2013, and the available quota for the full fiscal year was exceeded during the first week. Many advocates of higher rates of high-skilled immigration use the phrase "national suicide" to describe this situation and the limited admissions of high-skilled workers compared to lowskilled immigrants. On the other hand, expansions of admissions are passionately opposed by critics who believe that skilled immigration is already too high.

We review in this paper academic work regarding the effects of global migration on innovation and entrepreneurship. Some studies draw directly upon these outcome variablessuch as patenting rates or firm starts - while others consider employment and wages in related Science, Technology, Engineering, and Mathematics (STEM) fields and occupations. This review focuses exclusively on the United States' experience. In large part, this focus simply reflects where much of the work has been undertaken, and that the review attempts to cover multiple aspects of this phenomenon in relatively limited space. But this choice also reflects the 
comparative advantages of the author. The discussion attempts to highlight, at several points, the extent to which we can expect the discussed U.S. results to generalize to other settings. ${ }^{1}$

The first set of work considers descriptive traits about the phenomena. An uncontroversial fact from this discussion is that the "quantity" aspect of immigration to the United States with respect to innovation and entrepreneurship is substantial, especially in STEM fields. More debate emerges about the "quality" aspect. Studies take a range of perspectives, for example noting the disproportionate share of immigrants among U.S. Nobel Prize winners to the comparability of immigrants on patent citation counts. Recent work stresses the quality of foreign students in U.S. universities for STEM fields. We conclude that most immigrants engaged in STEM fields in the United States are better trained for this work than natives, but that they are comparable to each other conditional on education choices, with some greater potential for the long tail of superstars.

The second set of work considers the aggregate consequences of higher immigration to the United States for innovation. As a required stepping stone, this work also considers the employment consequences for native workers in STEM fields due to higher immigration. We further discuss entrepreneurship, but this has been less studied, excepting some descriptive statistics. The variation in research findings becomes even larger in this context compared to the quality dimension discussed above. Looking across the studies, we conclude that immigration is associated with higher levels of innovation for the United States and that the short-run consequences for natives are minimal. We also conclude, however, that this aggregate achievement involves some displacement of U.S. workers, and the long-run impact is less understood. The more important thrust of this review is that we are just beginning to trace out and quantify how the economy reacts to immigration. Most work thus far has followed a set of empirical techniques developed for analyzing immigration more broadly, and recent work emphasizes how the economics of high-skilled migration may be different. We describe promising avenues currently being explored and the attractive paths that lie ahead.

\footnotetext{
${ }^{1}$ Peri (2009) and Kuptsch and Pang (2006) discuss high-skilled immigration across a broader set of countries, and Bosetti et al. (2013) and Ozgen et al. (2011) provide recent empirical evidence from Europe. Several papers within this volume (e.g., Miguelez and Fink 2013, Özden and Parsons 2013, Lissoni 2013) discuss measurements of high-skilled immigration flows globally.
} 
The third set of work turns the focus outward, reviewing some basic work on how highskilled immigrants in the United States shape economic exchanges with their home countries. This discussion is fairly brief given that others are discussing these issues in this volume. At this point, it seems clear that high-skilled immigrants promote knowledge flows and foreign direct investments to their home countries, but it is unclear whether this benefit fully compensates the country for the potential negative consequences from the talent migration (e.g., Agrawal 2013). We likewise discuss return migration, but this is a second area where we know far less than we need to.

This line of work sits at the intersection of many fields. A large literature, surveyed by Docquier and Rapoport (2012), explores the multi-faceted consequences of the global migration of talented workers. Terms like "brain drain," "brain gain," etc., abound, and these net effects require consideration of many issues such as the presence of role models, the incentive consequences for human capital development, and similar. Innovation and entrepreneurship hold a special place in these discussions for multiple reasons, including their important link to longrun economic growth, the plausible claim that frontier economies provide talented migrants the best environment for their work (Kahn and MacGarvie 2013), and the attractiveness of these jobs for the native workers in these countries. More research around these topics is essential.

\section{Descriptive Traits}

The immigration of skilled workers is of deep importance to the United States. We first discuss the quantity dimension of this contribution - the share of workers engaged in entrepreneurship and innovation that are of immigrant origin. We then review the work on the "quality" dimension of these immigrants compared to natives.

\section{Immigrant Contributions to US Innovation and Entrepreneurship: Quantity}

It is often said that the United States is a land of immigrants. In the 2008 Current Population Survey, immigrants represent $16 \%$ of the U.S. workforce with a bachelor's education. Immigrants, moreover, account for $29 \%$ of the growth in this workforce during the 1995-2008 period. Exceeding these strong overall contributions, the role of immigrants within STEM fields is even more pronounced. In occupations closely linked to innovation and technology 
commercialization, the share of immigrants with bachelor's educations is almost $25 \%$. Moreover, Kerr and Lincoln (2010) estimate that immigrants account for a majority of the net increase in the U.S. STEM workforce since 1995.

Beyond these estimates of employments within STEM occupations that can be determined from population surveys or economic censuses, recent efforts describe immigrant shares in terms of patent counts or firm starts. A natural starting point is the United States Patent and Trademark Office (USPTO) database (Hall et al. 2001), given its comprehensive coverage of U.S. patent activity, but the USPTO unfortunately does not collect information on the immigration or citizenship status of inventors. To make progress, Kerr (2007) and Kerr and Lincoln (2010) develop estimates of ethnic inventor contributions (i.e., those of Chinese or Indian ethnic heritage). This work uses ethnic name matching procedures (e.g., inventors with the names Gupta or Desai are more likely to be of Indian ethnicity). This approach does not isolate immigration status directly for multiple reasons, ${ }^{2}$ but it does provide a very intuitive baseline. These papers emphasize the high degree of patenting contributions by ethnic inventors, its increase over time, and its particular importance for advanced technology fields. While Anglo-Saxon and European ethnic contributions account for $90 \%$ of total U.S. domestic patents in 1975 , they represent about $76 \%$ in 2004 . This declining share is primarily due to the exceptional growth over the 30 years of U.S. inventors of Chinese and Indian ethnicities, which increase from under $2 \%$ to $9 \%$ and $6 \%$, respectively. ${ }^{3}$

Immigrant contributions can also be estimated from the World Intellectual Property Organization (WIPO) database. This database has a narrower set of patents than the USPTO data, containing only those filed under the Patent Cooperation Treaty. The WIPO data record whether an inventor is a non-U.S. citizen, which is a lower bound on immigrants due to the

\footnotetext{
${ }^{2}$ Some important issues include the fact that names do not separate first- from later-generation immigrants, that some Anglo-Saxon ethnic inventors are immigrants (e.g., from Canada or the United Kingdom), that names can change with marriage, and that some key surnames like Lee can overlap with multiple ethnic groups. Nevertheless, the cited studies show that there is a good correspondence of the ethnic name classification approach to the decennial Census and similar quality assurance exercises.

${ }^{3}$ Kerr (2010b) describes the strong spatial contribution of these ethnic inventors in cities like San Francisco and Boston. Borjas (2001), Kerr (2010a), and Ruiz et al. (2012) describe how immigrants aid the reallocation of economic activity across places, with the latter two studies being focused on high-skilled migration in particular.
} 
naturalization process. Using WIPO data from 2006, Wadhwa et al. (2007a,b) find that non-U.S. citizens account for at least one inventor on $24 \%$ of international patent applications from the United States. This patent-level calculation includes inventions with multiple inventors so long as one inventor is a non-citizen, so this estimate is an upper bound on the aggregate role of noncitizens. Using ethnic name techniques to identify inventors of Chinese and Indian ethnic heritage, these authors also find strong contributions from these ethnic groups in particular. ${ }^{4}$

With respect to entrepreneurship, we know the contributions of immigrants are similarly large, although exact estimates remain more elusive. Saxenian (1999) finds that $24 \%$ of ventures in Silicon Valley during the 1980s and 1990s were run by Chinese or Indian bosses. In a followup piece, Wadhwa et al. (2007b) find that immigrants started 25\% of new high-tech companies with more than one million dollars in sales in 2006. Some of the survey methodologies in these studies have been criticized, but their results should remain roughly correct. A more important fact to bear in mind, similar to the above note for innovation, is that these figures are calculated across companies where at least one immigrant played a key role. Thus, by definition, the total contribution of immigrants is less than $25 \%$. These contributions are particularly strong in hightech fields. In an advocacy piece, Anderson and Platzer (2006) similarly find that immigrants represent $25 \%$ of founders of recent public venture-backed companies in the United States.

These studies shine the spotlight on high-growth entrepreneurship. For many, this focus is appropriate given the policy concern around fostering these entrepreneurs in particular. An example of this is the Start-Up Visa Act currently being discussed in the United States to provide easier admissions to immigrant entrepreneurs who are starting companies with high growth potential. The extensive sample selection for these studies, however, makes it harder to gauge the overall contributions of immigrants. Fairlee (2008) considers a broader landscape by returning to nationally representative survey databases like the Current Population Survey and the decennial Census. Fairlee finds that immigrants are about $30 \%$ more likely to start a business than nonimmigrants, and their share of current business ownership is on par with their population shares at $12 \%-13 \%$. Equally important, Fairlee's work describes the extensive range of immigrant

${ }^{4}$ The exceptional growth in immigrants' role discussed in this study are very difficult to interpret due to the large number of missing data pieces regarding nationality in early years of WIPO records. 
contributions. They play equally important roles in low- and high-skill sectors, reflective of the great range of immigrants admitted to the United States.

To summarize, immigrants represent an important and growing part of the U.S. workforce for innovation and entrepreneurship. We do not have every estimate that we would like, and our available estimates all have some issues with them. Nonetheless, the various approaches all speak to immigrants accounting for about a quarter of the general employment and output in these sectors for the United States, or perhaps a little less, with this share growing substantially since the 1970s. These contributions are heavily skewed towards certain technology areas and regions of the United States.

\section{Immigrant Contributions to US Innovation and Entrepreneurship: Quality}

Beyond their quantity role, how do immigrants compare to natives on the quality dimension? The answer to this question appears to be much more nuanced than the quantity discussion, and we review the evidence in stages. We start with evidence on aggregate workforce quality. We then move to more specialized aspects (e.g., Nobel Prize winners) and studies of student quality.

In a series of papers, Hunt and Gauthier-Loiselle (2010) and Hunt $(2011,2013)$ tackle some basic questions about whether immigrants are more innovative and entrepreneurial than natives as a whole, using a variety of representative data sources. A basic theme, most centrally discussed in Hunt (2011), is that immigrants who come to the United States for employment or study purposes have a large raw advantage over natives in terms of innovative outcomes (like filing a patent) and starting new companies. Hunt (2011) demonstrates, however, that choices around fields of study and educational attainment can explain most of these differences. This finding would suggest that quality differences between immigrants and natives, conditional on choosing to be involved in this area and pursuing it in school, are less important than the quantity factors described above. That is, it is not that immigrants are simply better than natives in STEM-related tasks in an absolute sense, but they do tend to make educational investments that lead them to be more involved in these areas. Interestingly, however, immigrants appear to retain some of their advantage for entrepreneurship, even conditional on education. In a subsequent piece, Hunt (2013) finds a similar nuanced theme. She argues that immigrants working in 
engineering occupations are performing better and obtaining higher wages than native engineers - being the "best and brightest" - thanks to their higher average education level. Among workers with an engineering degree, however, immigrants underperform natives, despite somewhat higher education, as they often work in occupations not commensurate with their education. $^{5}$

As a second approach to estimating these quality levels, Kerr and Lincoln (2010) compare the patents made by different ethnicities in terms of their quality as measured by patent claims. They find very comparable qualities for Anglo-Saxon and non-Anglo-Saxon ethnic inventors in the United States. Results contained in an early version of the Kerr et al. (2013) paper suggests that this comparability extends across many metrics of patent quality (e.g., forward citations, originality indices, shifts in focus from prior work of the firm).

Turning from these broad averages, an older literature considers the long-tail of the quality distribution. Stephan and Levin (2001) provide a well-known assessment in this regard, asking whether immigrants are disproportionately represented among individuals making exceptional STEM contributions. Across six indicators-for example, election to the National Academy of Sciences, the 250 most-cited authors, and authors of very highly-cited papers - they find very consistent evidence of immigrants being disproportionately represented. Wasmer et al. (2007) shows a similar disproportionate representation among immigrants in U.S. Nobel Prize winners.

Placing these first two themes together, it becomes clear that immigration acts in two different ways for the United States. First, it provides the United States with a number of exceptional superstars for STEM work. Second, immigration acts through the sheer quantity of workers that it provides for STEM fields. These workers are often well trained for STEM roles,

\footnotetext{
${ }^{5}$ A related descriptive fact is that immigrants account for almost half of the U.S. STEM workforce with doctorate educations, compared to a quarter at the bachelor's level. Other studies tend to find corroborating evidence to the first half of the Hunt (2011) thesis about the greater qualifications of immigrants. For example, Lofstrom and Hayes (2011) compare H-1B workers to native STEM workers in the United States, finding them to be younger and more educated. See also Mithas and Lucas (2010). It is important to note that these studies compare one immigrant group (H-1B workers) to all natives. This may be appropriate to the extent that we are contemplating an increase in the H-1B program's size. Hunt (2011) shows, however, that these types of immigrants are typically among the better skilled of immigrants, and thus broader depictions of immigrants versus natives may find the qualification differences weaker, similar to Fairlee's work.
} 
but, conditional on that education, the immigrants are of a similar quality level to U.S. natives. The pieces are not at odds with each other, as amid a large STEM workforce of more than two million workers, the exceptional tail does not move the averages of the groups very much. While it is difficult to prove which of these channels is more important, we have the general feeling that the quantity aspect of high-skilled immigration is the stronger factor in terms of its potential impact for STEM work in the United States.

To close, we also note a parallel set of work that considers the quantity and quality of immigrant student enrollments in STEM fields. This dimension is important as university and graduate school admissions shape, in large part, the United States' future STEM workforce. Bound et al. (2009) and similar studies document how immigrants account for an exceptional share of STEM students, especially among graduate students, in levels that exceed those noted for the workforce above. Grogger and Hanson (2013) describe the selectivity of foreign-born STEM Ph.D. students in the United States. Studies evaluating the production of innovation within universities also tend to find a special role for immigrant students (e.g., Chellaraj et al. 2008, Stephan 2010, Gurmu et al. 2010, Stuen et al. 2012, Gaule and Piacentini 2012). ${ }^{6}$

\section{Impact for U.S. Employment, Wages, and Innovation}

We next discuss studies regarding the impact of high-skilled immigrants on employment, wages, and innovation in receiving countries. In comparison to the descriptive pieces in the prior section, these studies attempt to incorporate into the analysis the net impact of migration for host countries inclusive of native responses. These latter impacts are often termed crowding-in or crowding-out effects, depending upon whether native employment increases or declines as a consequence of the immigration. While the overall theme of this review is innovation and entrepreneurship outcomes, these responses are intimately tied up with employment and wages. Absent exceptional quality differences for immigrants - which appear bounded by the descriptive elements outlined above - the increase or decrease of aggregate innovation due to immigration depends in large part on how immigrants affect the employment of natives.

${ }^{6}$ Weinberg (2011) and Hunter et al. (2009) provide recent evidence on the nature of outflows from countries (i.e., who sends). Docquier and Rapoport (2012) provide an extended discussion and review data sources regarding sending countries. 


\section{Traditional Approaches to Defining Labor Markets}

Traditionally, economists have evaluated these impacts using the conceptual lens of competitive labor markets (i.e., standard supply and demand curves for the services of workers). Immigration is modeled as an adjustment in the potential supply of labor to a market, shifting the labor supply curve outward, ceteris paribus. Reminiscent of an introductory economics course, the subsequent relative movements of the supply and demand curves determine the changes in the overall quantity of labor employed and the equilibrium wage rate. If the demand curve is fixed, the expansion in labor supply would be expected to increase employment and lower the equilibrium wage. These simple predictions do not hold under cases where labor demand adjusts in response to immigration, which in large part depends upon how quickly complementary inputs such as capital and other labor resources adjust. Likewise, other questions exist like whether natives move out of the labor markets in response to immigration, thereby dampening the supply increase and shifting the labor supply curve back towards its original position. Dustmann et al. (2008) and Lewis (2013) provide concise depictions and some recent evidence.

Researchers in high-skilled immigration have taken two main approaches for defining the labor market for such an analysis. A first approach, most closely following Card (2001), defines a labor market as a local area like a city or state. With this lens, immigrants to Chicago are thought to most directly impact the opportunities of natives currently living in Chicago. In the low-skilled immigration setting, this analysis is often done independent of occupation, with an explicit or implicit assumption that workers can move across occupations relatively easily. In the high-skilled immigration setting, especially related to innovation, occupations are more often seen as broadly fixed. Thus, often implicitly, the idea is to analyze the impact on native STEM workers in Chicago from STEM immigration to Chicago. ${ }^{7}$

Hunt and Gauthier-Loiselle (2010) apply this framework to high-skilled immigration by using state-decadal variation for the United States. These authors find very large crowding-in

${ }^{7}$ These studies do not capture well, if at all, the migration of workers out of the broad STEM occupation area. Some recent work with respect to trade and outsourcing suggest that the most hurt natives are those who must change occupations (e.g., Ebenstein et al. 2013). Using employer-employee data, Kerr and Kerr (2013) provide an initial study that describes the more difficult career transitions of native STEM workers leaving their jobs during periods of high rates of immigrant hiring into their former employers. 
effects, with big increases in innovation following upon immigration. Kerr and Lincoln (2010) consider city-level variations using annual changes in the $\mathrm{H}-1 \mathrm{~B}$ visa program. This study finds more modest effects, with increases in immigration yielding increases in innovation mainly through the immigrants themselves. Kerr and Lincoln (2010) find very limited evidence of crowding-in or crowding-out effects. The differences in magnitude between these studies can be traced to several factors (e.g., quite different time frames, methodological choices), but they nonetheless point in the same direction, overall, on the impact-immigration increases aggregate US innovation, with stable or rising native employment and wages. Peri et al. (2013) further find city-level productivity increases following from $\mathrm{H}-1 \mathrm{~B}$ program expansions in local areas that extensively rely on the program.

A second approach considers labor markets to be specialized fields of study or expertise (e.g., Friedberg 2001). This approach relaxes the geographic definition of the labor market and instead focuses on narrower fields of work. Two examples of this work with respect to highskilled immigration include Borjas and Doran's (2012) study of the migration of Russian mathematicians following the Soviet Union's collapse and Moser et al.'s (2012) study of Jewish scientist expellees from Nazi Germany. These studies analyze the impacts of variations in immigrant inflows to the United States within sub-fields of mathematics and chemistry, respectively, with the assumption of national labor markets within each sub-field. Despite conceptually similar designs, these studies find different outcomes. Borjas and Doran (2012) find that native mathematicians were crowded out by the Soviet influx, while Moser et al. (2012) find substantial long-run patenting growth, indicative of strong crowding-in effects after the Jewish influx. Both of these studies have credible experimental designs, and so this difference in direction of results is disconcerting even allowing for natural differences across fields of study and time periods. One part may be that the Borjas and Doran (2012) study is set in an institutional environment with limited room for overall growth. In this setting, crowd-out effects are more likely to exist (the labor demand curve becomes almost vertical). The chemistry fields and longer time horizons analyzed by Moser et al. (2012) may allow for a greater response, but this observation is very speculative and it is hoped that greater reconciliation is made going forward. 
A related approach to this sub-field analysis considers native choices of majors within schools, at either the undergraduate or graduate school levels. STEM occupations require extensive training and non-trivial switching costs, which may make forward-looking native students sensitive to immigrant inflows into fields of study. Freeman (1971) and Ryoo and Rosen (2004) describe the STEM labor market in greater detail. Borjas $(2005,2006)$ and Orrenius and Zavodny (2013) empirically examine the impact of immigrant students on native choices with respect to STEM fields, with the latter paper providing more extensive references. Lowell and Salzman (2007) and related work also considers the extent to which STEM-degree holders work in the STEM-related fields after schooling. Of the empirical approaches taken for estimating the consequences of immigration for natives, these studies of academic major choices appear to be the most likely to find natives leaving STEM fields as a response to immigration. We are not aware of studies with respect to schooling that find crowding-in type effects, with the existing studies either finding no effects or some measure of crowding-out.

Finally, Bound et al. (2013) provide a conceptually similar analysis by analyzing the employment and wage adjustments of computer scientists across two tech booms. The authors utilize a calibrated model instead of the empirical analysis that most studies employ in this field. Their results suggest that the substantial increase in immigration during the tech boom of the late 1990s, which was much larger in magnitude compared to the 1980s boom, led to less wage growth than what would otherwise have occurred. This study provides one of the first integrated models to consider the impact of high-skilled immigration on the economy. As the results of these types of calibrated frameworks depend significantly upon the specified structure of the model, others may naturally want to adjust some ingredients of the Bound et al. (2013) framework. We hope that other researchers build upon this analysis and continue to pursue integrated frameworks, as more research on this dimension is sorely needed.

Of these two main approaches for studying high-skilled immigration, it is hard to say whether one is more or less appropriate in terms of depicting the likely national response to higher immigration levels. Both types of studies conceptually rely on strict boundariesgeographies or specialties - and there are plenty of reasons why both sets of assumptions may be weaker than researchers hope. With the massive improvements in data, however, these 
assumptions may become more empirically quantifiable (e.g., Borjas and Doran 2013), which would be an aid in appropriate research design.

While this literature is quite small, studies using geographic areas appear to be more likely to find positive effects for natives from high-skilled immigration. While most discussions of the validity of local area studies for low-skilled immigration worry about the out-migration of natives, the opposite concern might exist for high-skilled migration. Since Alfred Marshall, economists have studied the clustering of firms that employ specialized workers or engage in knowledge-intensive activities. It is conceivable that high-skilled immigration to a city or state could engender greater native inflows due to agglomeration economies than what would be viable at a national level. Future research needs to evaluate whether relevant agglomeration economies are stronger or weaker at the national level. While it may initially seem clear that local agglomeration economies are larger, much of the current concerns over high rates of returnee STEM migration from the United States to countries like India and China center on a potential loss of U.S. technology leadership. The fear is less about losing individual scientists than losing a critical mass of frontier scientists, a process that would depend upon significant country-level agglomeration economies. Thus, we should not be too quick to assume a rank order of the spatial differences. ${ }^{8}$

A related conceptual issue pertains to applying these results to locations outside of the United States. Many European countries have one or a few leading cities (e.g., Helsinki, Finland) that are at least partially engaged in the European labor markets for STEM talent. In these cases, the impact of high-skilled immigration may draw elements from both the economics of individual cities, similar to the local area studies in the U.S. case, and the economics of national responses. An important avenue for future research is to consider these two dimensions simultaneously.

Predicting an empirical response to high-skilled immigration outside of the United States is also complicated by the fact that we do not know very much about the non-linear nature of the

\footnotetext{
${ }^{8}$ Recent work on historical transitions in scientific leadership, such as Waldinger (2010, 2013), may help shed light on these important issues. Papers from the agglomeration literature on the spatial dimension of knowledge flows include Audretsch and Feldman (1996), Rosenthal and Strange (2003), Arzaghi and Henderson (2008), and Ellison et al. (2010).
} 
returns-to-scale in these local technology clusters. Kerr and Lincoln (2010), for example, estimate that the patenting response to H-1B reforms in the top quintile of U.S. cities, in terms of program dependency, is about twice as strong as the second most dependent quintile. It may be more appropriate to benchmark potential experiences elsewhere off the second group of cities. In a similar manner, the estimates of Hunt and Gauthier-Loiselle (2010) that drop California may be a better measure for the potential experiences outside of the United States. ${ }^{9}$

\section{New Research Frontiers on the Labor Market Definitions}

We now consider several approaches to defining the labor market that show strong promise for future work (recognizing that most of the work and techniques reviewed to this point are very recent and will remain active research frontiers as well for years to come). A wellknown approach for studying the effects of general immigration, most closely associated with Borjas (2003), describes a national labor market among workers with similar education and age/experience profiles. With this lens, a 25-year-old immigrant with a bachelor's education in San Francisco may affect the opportunities of a 25-year-old native graduating from college in Chicago. Moreover, this effect may be larger than the effects of competition from older immigrants of a similar level of education who also live in Chicago. This approach has not been used for analyzing high-skilled immigration to date, in large part due to the fact that the highest education group in these frameworks is typically a bachelor's education or greater-a level which is usually taken as the starting point for defining skilled immigration. Most of the action and intense research inquiries have instead focused on dimensions like the substitution between high-school educated workers and those with some college education.

Recent research builds more "nesting" into these models. In the original study, Borjas (2003) allows for a single degree of substitutability across education-experience cells, with the implication being that a 30-year-old, college-educated worker is as distinct from a 20-year-old, college-educated worker as he or she is from a 50-year-old worker with a high-school diploma. With this assumption, the potential substitution between immigrants and natives can be analyzed

${ }^{9}$ A bigger focus in Europe has been on the role of ethnic diversity for innovation (e.g., Nathan 2012, Parrotta et al. 2013). 
within each cell. Recent approaches relax this assumption by describing levels of substitution (e.g., Ottaviano and Peri 2012, Borjas et al. 2012). For example, a researcher can specify that the first and highest level of substitution is across educational attainments of workers, the second level is by worker age/experience, and the third level is by immigration status. With this approach, empirical work can allow the 20- and 30-year-old workers with college educations to more closely substitute for each other in the example above. The nesting structure that is imposed on the data is very important and must be determined by the researcher, ideally with a good dose of sensitivity analysis.

While the nesting models are new, they may come to play an important role in the future study of high-skilled immigration. The nesting structure approach allows for richer analyses within the skilled worker groups themselves. Moreover, an attractive benefit of using this approach is that it requires researchers to better specify the economics of the interactions that they have in mind, even if they do not build a formal model. As an early example, Kerr et al. (2013) consider the degree of substitution that exists across age groups. Prominent advocates against the H-1B visa program claim that tech firms use the program to keep their workforces younger, in part to lower wage bills. ${ }^{10}$ This claim is impossible to evaluate in the frameworks described earlier. While advocates against immigration cite the Borjas (2003) crowd-out results, this paper's framework does not incorporate the types of substitution proposed to be the most important by many H-1B critics.

To analyze this feature, Kerr et al. (2013) conceptually lay out a nesting scenario, exclusively among skilled workers with college degrees or higher, where the top-level is occupations, the second level is worker age/experience, and the third level is immigration status. The study then estimates the elasticity of substitution across age groups within each occupation using the Current Population Survey from 1995-2008. These estimates reveal that the elasticity of substitution across age groups is substantially higher in STEM-related fields than among other workers. STEM fields account for three of the four highest elasticities among occupations, and

\footnotetext{
${ }^{10}$ Matloff (2003) proposes that the H-1B program offers firms two types of potential savings. One type of savings centers on the fact that a 25-year-old Indian H-1B programmer might be paid less than a 25-year-old American programmer. He argues that this emphasis is entirely misplaced and that the real savings to the firm come instead from displacing a 50-year-old American programmer whose salary has grown with time.
} 
are greater than those in fields like law or accounting. Higher elasticities of substitution by age for STEM occupations give one indication as to why older natives may experience displacement from young immigrants in STEM fields. In the nesting format, the results say that the age boundary between young immigrants and older natives may be more porous among STEM fields than in other occupations where a very low elasticity across age groups means that young immigrants effectively have the most impact on young natives in the same occupation.

A second line of work considers movements of high-skilled natives across fields in response to immigration. Peri and Sparber (2011) consider the potential shift of native educated workers across occupations in response to immigration inflows. The authors find that immigrants with graduate degrees specialize in occupations demanding quantitative and analytical skills, while the native workers move into occupations requiring interactive and communication skills. When the foreign-born proportion of highly educated employment within an occupation rises, native employees with graduate degrees choose new occupations with less analytical and more communicative content. In a quite different context, Borjas et al. (2013) also consider native mobility across mathematical sub-fields in response to the Soviet influx. They demonstrate how native mathematicians shifted into fields where the Soviet mathematicians were less active before the influx, especially those mathematicians that were not superstars.

These studies do not fit directly within the empirical frameworks depicted above, as they describe mobility across occupations or fields that the other studies typically assume is not happening. Nonetheless, they and the nesting structure work share a common motivation to advance our depictions of these impacts beyond strictly-defined labor markets. This is extremely important and represents the first steps of the economics of high-skilled immigration in establishing its own frameworks beyond those traditionally used to study broad consequences of immigration. For many reasons, such as the required educational and training investments for STEM work, high-skilled immigration research needs to continue to define its own approaches and techniques in order to achieve a full characterization of this phenomenon. Theoretical frameworks that guide these steps are in high demand.

These new results and approaches can also be challenging to interpret. For example, the Peri and Sparber (2011) results can be viewed in a positive manner by describing complementary skills of immigrants and natives. Others, however, could interpret the results as demonstrating 
crowd-out effects from the technical fields, even if there are not adverse employment or wage consequences for the natives that have chosen different career paths. Developing a better conceptual framework to interpret these patterns may be as important as the additional empirical evidence. A starting point might be the literature on "scientists paying to be scientists" following Stern (2004). It also appears that economists studying high-skilled immigration will increasingly encounter normative questions that go beyond measurement: for example, if the native worker obtains the same or higher salary moving to another field due to expanding immigration, do we consider this to be a crowding-out phenomenon? What if the native preferred the original field holding money constant?

\section{The Role of the Firm}

Kerr et al. (2013) argue that the study of high-skilled immigration needs to consider more deeply the role of the firm. A focus on firms represents a substantial departure from the conceptual lens of a competitive labor market described above, where immigration is framed as an exogenous potential outward shift of the labor supply curve and representative firms have some underlying demand for workers. From an empirical perspective as well, firms and other institutions that employ the immigrants are also rarely mentioned.

This is quite striking since U.S. firms play a central role in the immigration process for high-skilled workers. A prime example is the $\mathrm{H}-1 \mathrm{~B}$ visa, which is the largest program for temporary skilled immigration to the United States. To begin, the H-1B is a firm-sponsored visa, meaning that a company first identifies the worker that it wants to hire. The firm then applies to the U.S. government to obtain a visa and pays the associated fees on behalf of that specific worker. This worker can come from anywhere in the world, and while the application procedure does have requirements with respect to the local area in which the employee will work in the United States, these conditions are primarily non-equilibrium in nature. The visa has a regulated supply that lacks a pricing mechanism and is sometimes allocated by lottery. Finally, once the work has started, the immigrant is effectively tied to the firm until obtaining permanent residency or obtaining another temporary visa. The firm can potentially sponsor the employee for a green card, a process that takes six years or longer for some nationalities, during which time the employee is even more closely tied to the firm. 
This depiction highlights the strong role that firms play in these admissions. The structure of the high-skilled immigration program is designed in part to allow firms to select the workers that they want to hire, rather than having employment-based immigrants to the United States be selected by the U.S. government. Moreover, most of the arguments in the public debate about the impact of skilled immigration in the United States are firm-level statements. ${ }^{11}$ Given this policy framework, it seems particularly valuable to understand exactly how the visas are used within the sponsoring firms. (It also makes a lot of sense for us to spend more time researching the universities that are a key source of initial immigration inflows into the economy, with the work noted earlier about university innovation as an important starting point.)

The recent availability of large employer-employee datasets allows researchers to consider these views in greater detail, and Kerr et al. (2013) analyzes the U.S. experience using the Longitudinal Employer-Household Dynamics database. The study finds that the increased employment of young skilled immigrants raises the overall employment of high-skilled workers in the firm, increases the immigrant share of these workers, and reduces the older worker share of skilled employees. The latter effect is evident even among natives only and connects to the nesting framework of age elasticities described above. The study finds that the expansion of young high-skilled immigrant employment does not result in significant growth of employment for older high-skilled workers, but the evidence also suggests that absolute declines in employment of this group are not likely. These estimates suggest that age is an important dimension on which firms make decisions and that there may be lower complementarity between young high-skilled immigrants and older domestic workers.

The development of new employer-employee data offers great promise for expanding our understanding of the high-skilled immigration process from both empirical and theoretical perspectives. The literature on international trade, for example, has benefited tremendously over the last decade from greater consideration of the role of the firm and the heterogeneities across firms. It is likely that studies of high-skilled immigration can undergo a similar transformation.

\footnotetext{
${ }^{11}$ For example, Bill Gates has stated in congressional testimony that Microsoft hires four additional employees to support each H-1B worker hired. On the other hand, Matloff (2003) and Hira (2010) criticize specific displacement that is occuring within firms due to the hiring of H-1B workers. Kerr et al. (2011) consider firm-level lobbying on behalf of high-skilled immigration.
} 
This is also an area where work outside of the United States is feasible and to be encouraged. For example, Nokia has played an enormous role in skilled immigration to Finland, and many other countries have similar experiences.

\section{Turning the Attention Outward}

We close this review with some broader thoughts about the global connections of these migrants. Given the other conference reports on these dimensions, this discussion is less comprehensive that the analyses so far, but the U.S.-specific studies help complete a perspective on the global migrations to the United States.

\section{The Importance of Place}

In the introduction, we briefly mentioned the plausible claim that frontier economies provide STEM immigrants the best environment for their work. This is important to the extent that technologies that immigrants produce in the United States can be shared throughout the world. Placing aside difficult questions about diffusion lags and intellectual property protection rights (e.g., Naghavi 2013, Kaboré 2013), allowing the migration of skilled talent to places where those skills can be best utilized provides a foundation for greater prosperity for all. This is true within countries, with great entrepreneurial talent flowing to Silicon Valley from many parts of the United States, and the same gains can happen across countries. Two recent studies provide an interesting perspective on these issues.

Kahn and MacGarvie (2013) compare foreign-born U.S.-educated scientists that must relocate outside of the United States after their doctoral studies due to exogenous reasons related to their student visa restrictions, compared to their foreign-born peer students that are allowed to stay in the United States. In terms of publications and citation counts, Kahn and MacGarvie (2013) find that graduates forced to re-locate outside of the U.S. perform much worse if they must locate to a place with low income per capita. However, the authors also find a scientist exogenously located in a country at the top of the income distribution can expect to be as productive in research as he or she would be in the United States. These patterns accord with the much higher stay rates that we observe for foreign students from low income countries compared to places like Western Europe. 
Clemens (2013) considers international differences in workers' wages and productivity. He exploits the randomized processing of U.S. H-1B visas for a group of Indian workers who produce software within a single multinational firm. When applications for U.S. H-1B visas exceed the annual cap set by the government within the first week (similar to fiscal year 2014), a lottery is conducted over the applications to award the limited positions. Clemens' personnel records contain the winners and losers in the lottery for the multinational firm. Clemens finds that the winners' salary increases six-fold upon relocating to the United States with the visa. Given the randomization of the lottery and the fact that the winning and denied applicants are doing the same kind of work for the multinational firm, Clemens argues that country-of-work by itself is responsible - in this industry - for roughly three-quarters of the gap in productivity between workers in India and workers in the richest countries.

\section{Connections to Home Countries}

These findings that immigrants are more productive in advanced economies provide support for beneficial effects of migration, but they stop short of saying that overseas populations aid their home countries. Several studies suggest home countries receive some economic benefits from having STEM workers in the United States. (In turn, these studies stop short of saying that these economic benefits offset potential negative consequences of the out-migration of talentthis review will skip such a complicated adding-up exercise given the vastly incomplete evidence accumulated to date, much less our ignorance about how to weight the various factors involved.)

Saxenian et al. (2002) provide a well-known survey of immigrant scientists and engineers living in Silicon Valley. These surveys, while very unrepresentative for all immigrants, offer some sense of the relative forms of these contributions. Saxenian documents that $82 \%$ of Chinese and Indian immigrant STEM workers report exchanging technical information with their respective nations, roughly $50 \%$ of immigrants report aiding the development of contracts or business relationships between the United States and their home countries, and 18\% report investing in overseas business partnerships. Saxenian's estimates clearly overstate the homecountry exchanges of all immigrants, given the specialized nature of her sample, but the key question is by how much. 
Beginning with knowledge flows, more systematic studies with patent citation data suggest that immigrant STEM workers in the United States can aid technology transfer to their home countries (e.g., Kerr 2008, Agrawal et al. 2011, Oettl and Agrawal 2008). Kerr (2008) emphasizes that these ethnic transmission channels are particularly powerful in the first five to seven years after a new technology is developed. Agrawal et al. (2011) find that the Indian diaspora in the United States aids its home country the most with the development of big, highlycited inventions, but that the diaspora is not as helpful in the production of average inventions as a larger domestic base of inventors. Agrawal (2013) picks up and expands upon these themes.

Turning to other forms of business exchanges, a long literature considers the role of ethnic networks in trade patterns (e.g., Rauch and Trindade 2002), and Rauch (2001) and Keller (2004) provide important reviews of related literatures. We are not aware of any studies that have validated this for the United States in particular, similar to the firm-level documentation in Europe (e.g., Hatzigeorgiou and Lodefalk 2011), but it is reasonable to suspect it exists. A similarly long literature documents the link between ethnic networks and foreign direct investments (FDI) across countries (e.g., Kugler and Rapoport 2007, 2011; Kim and Park 2013). Foley and Kerr (2013) document this pattern with respect to ethnic inventors using firm-level data from the Bureau of Economic Analysis. Their analysis in particular emphasizes the role of ethnic inventors in the United States for helping their employers develop R\&D-based work abroad and enter into foreign countries without the support of local joint venture partners, perhaps due to better knowledge of the home country. Foley and Kerr (2013) also provide a more extensive literature set on both the trade and FDI channels.

Beyond trade and FDI, additional work considers the role of immigrants in the outsourcing of work. One way that diasporas are thought to connect with their home country is by facilitating the outsourcing of work (with special emphasis often given to India). It is felt, for example, that the U.S.-based members of an ethnic group can provide knowledge about opportunities to their home countries, serve as reputational intermediaries, facilitate contracts, and similar. Hira (2010) argues that this relationship is true (in a negative way), and moreover that the H-1B visa is particularly used as a vehicle for outsourcing by bringing immigrants to the United States for training in the jobs to be conducted overseas. There certainly appears to be truth to this claim, as the top three H-1B applicants in 2013 for H-1B visas were Indian 
outsourcing firms, with Infosys (\#1) applying for three times more visas than Microsoft (\#6). Beyond this high-profile approach of dedicated outsourcing firms, the relationship becomes less clear. Using data from oDesk, the world's largest on-line platform for outsourcing, Ghani et al. (2013) find evidence of ethnic Indians being more likely to send to work to India when outsourcing jobs. These authors also suggest, however, that the Indian diaspora's role was likely modest in the overall rise of India as the top outsourcing destination on oDesk. ${ }^{12}$

To summarize, studies of the United States find a fair amount of evidence that immigrants continue to interact with their home countries after coming to the United States. These exchanges by themselves are insufficient to conclude that a "brain gain" exists, but they are likely a necessary element. More research and modeling (e.g., Agrawal et al. 2011, Docquier and Rapoport 2012) is necessary to add this up, which will of course be specific to each country and circumstance.

\section{Return Migration}

We close by noting an area where we really wish we knew more: return migration. Immigration has always been a temporary step for many, and recent case studies and surveys describe the important migration of skilled workers back to home countries (e.g., Saxenian 2006, Wadhwa et al. 2009). ${ }^{13}$ At this point, we know that this return migration from the United States is happening for a variety of reasons, most notably the increased attractiveness of foreign locations on personal and professional levels. Restrictive U.S. immigration policy plays a role, but this role is likely secondary to the attractive opportunities seen for many in returning home. Given the exceptional importance of immigrants for work in U.S. STEM fields, this trend could challenge the United States' role in technology leadership. Alas, while countries measure inflows of people reasonably well, outflows of people are measured very poorly, it at all. For the United States, clever data work to further quantify these features would be most welcome.

\footnotetext{
12 Ottaviano et al. (2013) consider the interactions between low-skilled immigration and outsourcing using a trade-in-tasks model. Further work with these types of models and high-skilled immigration would be very useful.

${ }^{13}$ Related work includes Nanda and Khanna (2010) and Hovhannisyan and Keller (2010). Return migration among immigrants more broadly is better studied (e.g., Dustmann (1996) and later work) than the high-skilled group on which this review focuses.
} 


\section{Conclusions}

The global migration of STEM talent is exceptionally important — and sadly understudied compared to this importance. This review, while not intended in this way, has mostly progressed from things we have a relatively good handle on for the United States (e.g., the quantity and quality of immigrants) to pieces that we have very little insight on (e.g., return migration). We hope that future research helps fill-in this portrait and provides us a sharper platform for policy advice. We overall conclude, as many others have, that immigration has been essential for the United States' leadership in innovation and entrepreneurship. We also generally find evidence of positive impacts of high-skilled diasporas for home countries, recognizing that the ledger that can be measured in the United States is incomplete.

\section{Appendix: H-1B Visa Program}

This is an abbreviated description from Kerr and Lincoln (2010): The H-1B visa is a temporary immigration category that allows U.S. employers to seek short-term help from skilled foreigners in "specialty occupations." These occupations are defined as those requiring theoretical and practical application of specialized knowledge like engineering or accounting; virtually all successful H-1B applicants have a bachelor's education or higher. The visa is used especially for STEM-related occupations, which account for roughly $60 \%$ of successful applications. Approximately $40 \%$ and $10 \%$ of H-1B recipients over 2000-2005 came from India and China, respectively. Shares for other countries are less than $5 \%$.

The sponsoring firm files the H-1B application and must specify an individual candidate. The employeremployee match must therefore be made in advance. Workers are tied to their sponsoring firm, although some recent changes have increased visa portability. Firms can petition for permanent residency (i.e., a green card) on behalf of the worker. If permanent residency is not obtained, the H-1B worker must leave the United States at the end of the visa period for one year before applying again. Firms are also required to pay the visa holder the higher of (1) the prevailing wage in the firm for the position or (2) the prevailing wage for the occupation in the area of employment. These restrictions were designed to prevent $\mathrm{H}-1 \mathrm{~B}$ employers from abusing their relationships with foreign workers and to protect domestic workers.

Since the Immigration Act of 1990, there has been an annual cap on the number of H-1B visas that can be issued. The cap governs new $\mathrm{H}-1 \mathrm{~B}$ visa issuances only; renewals for the second three-year term are exempt, and the maximum length of stay on an H-1B visa is thus six years. While most aspects of the $\mathrm{H}-$ 1B program have remained constant since its inception, the cap has fluctuated significantly and is the source of extensive controversy. The original 65,000 cap was not binding in the early 1990s but became so by the middle of the decade. Legislation in 1998 and 2000 sharply increased the cap over the next five years to 195,000 visas. These short-term increases were allowed to expire during the United States' hightech downturn, when visa demand fell short of the cap. The cap returned to the 65,000 level in 2004 and became binding again, despite being subsequently raised by 20,000 through an "advanced degree" exemption. This $65,000+20,000$ structure remains today. 


\section{References}

Agrawal, Ajay, "Diaspora Networks, Knowledge Flows, and Brain Drain”, WIPO Chapter (2013).

Agrawal, Ajay, Devesh Kapur, John McHale, and Alexander Oettl, "Brain Drain or Brain Bank? The Impact of Skilled Emigration on Poor-Country Innovation", Journal of Urban Economics 69 (2011), 43-55.

Anderson, Stuart, and Machaela Platzer, "American Made: The Impact of Immigrant Entrepreneurs and Professionals on U.S. Competitiveness", National Venture Capital Associate Report (2006).

Arzaghi, Mohammad, and J. Vernon Henderson, "Networking off Madison Avenue", Review of Economic Studies 75:4 (2008), 1011-1038.

Audretsch, David, and Maryann Feldman, "R\&D Spillovers and the Geography of Innovation and Production", American Economic Review 86 (1996), 630-640.

Borjas, George, "Does Immigration Grease the Wheels of the Labor Market?", Brookings Papers on Economic Activity 2001:1 (2001), 69-119.

Borjas, George, "The Labor Demand Curve Is Downward Sloping: Reexamining the Impact of Immigration on the Labor Market", Quarterly Journal of Economics 118:4 (2003), 1335-1374.

Borjas, George, "Do Foreign Students Crowd Out Native Students from Graduate Programs?", in Ronald Ehrenberg and Paula Stephan (eds.), Science and the University (Madison, WI: University of Wisconsin Press, 2005).

Borjas, George, "Immigration in High-Skill Labor Markets: The Impact of Foreign Students on the Earnings of Doctorates", NBER Working Paper 12085 (2006).

Borjas, George, and Kirk Doran, "The Collapse of the Soviet Union and the Productivity of American Mathematicians", Quarterly Journal of Economics 127:3 (2012), 1143-1203.

Borjas, George, and Kirk Doran, "Intellectual Mobility: Native Responses to Supply Shocks in the Space of Ideas", Journal of Labor Economics (2013), forthcoming.

Borjas, George, Jeffrey Grogger, and Gordon Hanson, "Comment: On Estimating the Elasticities of Substitution”, Journal of the European Economic Association 10:1 (2012), 198-210.

Borjas, George, Jeffrey Grogger, and Gordon Hanson, "Comment: On Estimating the Elasticities of Substitution", Journal of the European Economic Association 10:1 (2012), 198-210.

Bosetti, Valentina, Cristina Cattaneo, and Elena Verdolini, "Migration of Skilled Workers and Innovation: A European Perspective", Working Paper (2013).

Bound, John, Breno Braga, and Joseph Golden, "Recruitment of Foreigners in the Market for Computer Scientists in the US", Working Paper (2013).

Card, David, "Immigrant Inflows, Native Outflows, and the Local Labor Market Impacts of Higher Immigration", Journal of Labor Economics 19:1 (2001), 22-64.

Chellaraj, Gnanaraj, Keith Maskus, and Aaditya Mattoo, "The Contribution of Skilled Immigrations and International Graduate Students to U.S. Innovation”, Review of International Economics 16:3 (2008), 444-462.

Clemens, Michael, "Economics and Emigration: Trillion-Dollar Bills on the Sidewalk?", Journal of Economic Perspectives 25:3 (2011), 83-106.

Clemens, Michael, "Why Do Programmers Earn More in Houston than Hyderabad? Evidence from Randomized Processing of U.S. Visas", American Economic Review Papers \& Proceedings 103:3 (2013), 198-202.

Docquier, Frederic, and Hillel Rapoport, "Globalization, Brain Drain, and Development", Journal of Economic Literature 50:3 (2012), 681-730.

Dustmann, Christian, "Return Migration: The European Experience", Economic Policy 22 (1996), 215 250 . 
Dustmann, Christian, Albrecht Glitz, and Tommaso Frattini, "The Labour Market Impacts of Immigration", Oxford Review of Economic Policy 24:3 (2008), 477-494.

Ebenstein, Avraham, Ann Harrison, Margaret McMillan, and Shannon Phillips, "Why Are American Workers Getting Poorer? Estimating the Impact of Trade and Offshoring Using the CPS", Working Paper (2013).

Ellison, Glenn, Edward Glaeser, and William Kerr, "What Causes Industry Agglomeration? Evidence from Coagglomeration Patterns", American Economic Review 100 (2010), 1195-1213.

Fairlee, Robert, "Estimating the Contribution of Immigrant Business Owners to the U.S. Economy", Small Business Administration, Office of Advocacy Report (2008).

Foley, Fritz, and William Kerr, "Ethnic Innovation and U.S. Multinational Firm Activity", Management Science 59:7 (2013), 1529-1544.

Freeman, Richard, The Market for College-Trained Manpower: A Study in the Economics of Career Choice (Cambridge, MA: Harvard University Press, 1971).

Freeman, Richard, "People Flows in Globalization”, Journal of Economic Perspectives 20:2 (2006), 145170.

Friedberg, Rachel, "The Impact of Mass Migration on the Israeli Labor Market", Quarterly Journal of Economics 116:4 (2001), 1373-1408.

Gaule, Patrick, and Mario Piacentini, "Chinese Graduate Students and U.S. Scientific Productivity", Review of Economics and Statistics (2012), forthcoming.

Ghani, Ejaz, William Kerr, and Christopher Stanton, "Diasporas and Outsourcing: Evidence from oDesk and India", Management Science (2013), forthcoming.

Grogger, Jeffrey, and Gordon Hanson, "The Scale and Selectivity of Foreign Born Ph.D. Recipients in the U.S.”, American Economic Review Papers and Proceedings 103:3 (2013), 189-192.

Gurmu, Shiferaw, Grant Black, and Paula Stephan, "The Knowledge Production Function for University Patenting", Economic Inquiry 48:1 (2010), 192-213.

Hall, Bronwyn, Adam Jaffe, and Manuel Trajtenberg, "The NBER Patent Citation Data File: Lessons, Insights and Methodological Tools", NBER Working Paper 8498 (2001).

Hatzigeorgiou, Andreas, and Magnus Lodefalk, "Trade and Migration: Firm-Level Evidence”, Working Paper (2011).

Hira, Ron, "The H-1B and L-1 Visa programs: Out of Control”, EPI Policy Paper (2010).

Hovhannisyan, Nune, and Wolfgang Keller, "International Business Travel: An Engine of Innovation?", Working Paper (2010).

Hunt, Jennifer, "Which Immigrants are Most Innovative and Entrepreneurial? Distinctions by Entry Visa", Journal of Labor Economics 29:3 (2011), 417-457.

Hunt, Jennifer, "Does the United States Admit the Best and Brightest Computer and Engineering Workers", Working Paper (2013).

Hunt, Jennifer, and Marjolaine Gauthier-Loiselle, "How Much Does Immigration Boost Innovation?", American Economic Journal: Macroeconomics 2:2 (2010), 31-56.

Hunter, Rosalind, Andrew Oswald, and Bruce Charlton, “The Elite Brain Drain”, The Economic Journal 119 (2009), F231-F251.

Kaboré, François, "Brain Drain, Intellectual Property Rights and Development in Africa", WIPO Chapter (2013).

Kahn, Shulamit, and Megan MacGarvie, "How Important is U.S. Location for Research in Science?", Review of Economics and Statistics (2013), forthcoming. 
Keller, Wolfgang, "International Technology Diffusion", Journal of Economic Literature 42:3 (2004), 752-782.

Kerr, Sari Pekkala, and William Kerr, "Immigration and Employer Transitions for STEM Workers", American Economic Review Papers and Proceedings 103:3 (2013), 193-197.

Kerr, Sari Pekkala, William Kerr, and William Lincoln, "Skilled Immigration and the Employment Structures of U.S. Firms", Working Paper (2013).

Kerr, William, "The Ethnic Composition of U.S. Inventors", Harvard Business School Working Paper 08-006 (2007).

Kerr, William, "Ethnic Scientific Communities and International Technology Diffusion", Review of Economics and Statistics 90:3 (2008), 518-537.

Kerr, William, "Breakthrough Inventions and Migrating Clusters of Innovation", Journal of Urban Economics 67:1 (2010a), 46-60.

Kerr, William, "The Agglomeration of U.S. Ethnic Inventors", in Edward Glaeser (ed.) Agglomeration Economics (Chicago, IL: University of Chicago Press, 2010b), 237-276.

Kerr, William, and William Lincoln, "The Supply Side of Innovation: H-1B Visa Reforms and U.S. Ethnic Invention", Journal of Labor Economics 28:3 (2010), 473-508.

Kerr, William, William Lincoln, and Prachi Mishra, “The Dynamics of Firm Lobbying”, NBER Working Paper 17577 (2011).

Kim, Jinyoung, and Jungsoo Park, "Foreign Direct Investment and Country-Specific Human Capital," Economic Inquiry 51:1 (2013), 198-210.

Kim, Jinyoung, Sangjoon Lee, and Gerald Marschke, "Inventor Productivity and Firm Size: Evidence from Panel Data on Inventors," Pacific Economic Review 14:4 (2009), 516-531.

Kugler, Maurice, and Hillel Rapoport, "International Labor and Capital Flows: Complements or Substitutes?", Economics Letters 92:2 (2007), 155-162.

Kugler, Maurice, and Hillel Rapoport, "Migration, FDI and the Margins of Trade", Working Paper (2011).

Kuptsch, Christiane, and Eng Fong Pang, Competing for Global Talent, International Labour Organization (International Institute for Labour Studies, 2006).

Lewis, Ethan, "Immigration and Production Technology", Annual Review of Economics 5 (2013), forthcoming.

Lissoni, Francesco, "Inventor Data for Research on Migration and Innovation: A Survey and a Pilot", WIPO Chapter (2013).

Lofstrom, Magnus, and Joseph Hayes, "H-1Bs: How Do They Stack Up to US Born Workers", IZA Working Paper 6259 (2011).

Lowell, B. Lindsay, and Hal Salzman, "Into the Eye of the Storm: Assessing the Evidence on Science and Engineering Education, Quality, and Workforce Demand", Working Paper (2007).

Matloff, Norman, "On the Need for Reform of the H-1B Non-Immigrant Work Visa in Computer-Related Occupations", University of Michigan Journal of Law Reform 36:4 (2003), 815-914.

Miguelez, Ernest, and Carsten Fink, "Measuring the International Mobility of Inventors: A New Database", WIPO Chapter (2013).

Mithas, Sunil, and Henry Lucas, "Are Foreign IT Workers Cheaper? U.S. Visa Policies and Compensation of Information Technology Professionals”, Management Science 56 (2010), 745765.

Moser, Petra, Alessandra Voena, and Fabian Waldinger, "German Jewish Émigrés and U.S. Invention”, Working Paper (2012). 
Naghavi, Alireza, "Intellectual Property Protection and the Brain Drain", WIPO Chapter (2013).

Nanda, Ramana, and Tarun Khanna, "Diasporas and Domestic Entrepreneurs: Evidence from the Indian Software Industry", Journal of Economics and Management Strategy 19:4 (2010), 991-1012.

Nathan, Max, "Ethnic Inventors, Diversity and Innovation in the UK: Evidence from Patents Microdata", Working Paper (2012).

Oettl, Alexander, and Ajay Agrawal, "International Labor Mobility and Knowledge Flow Externalities", Journal of International Business Studies 39:8 (2008), 1242-1260.

Orrenius, Pia, and Madeline Zavodny, "Does Immigration Affect whether U.S. Natives Major in a STEM Field?", Working Paper (2013).

Ottaviano, Gianmarco, and Giovanni Peri, "Rethinking the Effect of Immigration on Wages", Journal of the European Economic Association 10:1 (2012), 152-197.

Ottaviano, Gianmarco, Giovanni Peri, and Greg Wright, "Immigration, Offshoring, and American Jobs", American Economic Review (2013), forthcoming.

Özden, Çaglar, and Christopher Parsons, "International Mobility of Knowledge Workers and HighSkilled Migration”, WIPO Chapter (2013).

Ozgen, Ceren, Peter Nijkamp, and Jacques Poot, "Immigration and Innovation in European Regions", IZA Working Paper 5676 (2011).

Parrotta, Pierpaolo, Dario Pozzoli, and Mariola Pytlikova, "The Nexus between Labor Diversity and Firm's Innovation", Working Paper (2013).

Peri, Giovanni, "The Determinants and Effects of Highly-Skilled Labor Movements: Evidence from OECD Countries 1980-2005”, CEPR Report (2009).

Peri, Giovanni, Kevin Shih, and Chad Sparber, "STEM Workers, H-1B Visas and Productivity in US Cities", Working Paper (2013).

Peri, Giovanni, and Chad Sparber, "Highly-Educated Immigrants and Native Occupational Choice", Industrial Relations 50:3 (2011), 385-411.

Rauch, James, "Business and Social Networks in International Trade", Journal of Economic Literature 39:4 (2001), 1177-1203.

Rauch, James, and Vitor Trindade, "Ethnic Chinese Networks in International Trade", Review of Economics and Statistics 84:1 (2002), 116-130.

Rosenthal, Stuart, and William Strange, "Geography, Industrial Organization, and Agglomeration", Review of Economics and Statistics 85:2 (2003), 377-393.

Ruiz, Neil, Jill Wilson, and Shyamali Choudhury, "Geography of H-1B Workers: Demand for HighSkilled Foreign Labor in U.S. Metropolitan Areas”, Brookings Report (2012).

Ryoo, Jaewoo, and Sherwin Rosen, “The Engineering Labor Market”, Journal of Political Economy 112:2 (2004), S110-S140.

Saxenian, AnnaLee, Silicon Valley's New Immigrant Entrepreneurs (San Francisco, CA: Public Policy Institute of California, 1999).

Saxenian, AnnaLee, The New Argonauts (Cambridge, MA: Harvard University Press, 2006).

Saxenian, AnnaLee, with Yasuyuki Motoyama and Xiaohong Quan, Local and Global Networks of Immigrant Professionals in Silicon Valley (San Francisco, CA: Public Policy Institute of California, 2002).

Stephan, Paula, "The I's Have It: Immigration and Innovation, the Perspective from Academe", in Josh Lerner and Scott Stern (eds.) Innovation Policy and the Economy (Cambridge, MA: MIT Press, 2010). 
Stephan, Paula, and Sharon Levin, "Exceptional Contributions to US Science by the Foreign-Born and Foreign-Educated", Population Research and Policy Review 20:1 (2001), 59-79.

Stern, Scott, "Do Scientists Pay to be Scientists?", Management Science 50:6 (2004), 835-853.

Stuen, Eric, Ahmed Mobarak, and Keith Maskus, "Skilled Immigration and Innovation: Evidence from Enrollment Fluctuations in U.S. Doctoral Programs", Economic Journal 122:565 (2012), 11431176.

Wadhwa, Vivek, Guillermina Jasso, Ben Rissing, Gary Gereffi, and Richard Freeman, "Intellectual Property, the Immigration Backlog, and a Reverse Brain-Drain”, Kauffman Foundation Report (2007a).

Wadhwa, Vivek, AnnaLee Saxenian, Richard Freeman, and Gary Gereffi, “America's Loss is the World's Gain: America's New Immigrant Entrepreneurs, Part 4", Kauffman Foundation Report (2009).

Wadhwa, Vivek, AnnaLee Saxenian, Ben Rissing, and Gary Gereffi, "America's New Immigrant Entrepreneurs", Kauffman Foundation Report (2007b).

Waldinger, Fabian, "Quality Matters: The Expulsion of Professors and the Consequences for PhD Students Outcomes in Nazi Germany", Journal of Political Economy 118:4 (2010), 787-831.

Waldinger, Fabian, "Bombs, Brains, and Science: The Role of Human and Physical Capital for the Creation of Scientific Knowledge", Working Paper (2013).

Wasmer, Etienne, Paul Fredriksson, Ana Lamo, Julian Messina, and Giovanni Peri, "The Macroeconomics of Education in Europe" in Brunello, Garibaldi, and Wasmer (eds.) Education and Training in Europe (Oxford: Oxford University Press, 2007).

Weinberg, Bruce, "Developing Science: Scientific Performance and Brain Drains in the Developing World", Journal of Development Economics 95:1 (2011), 95-104. 